\title{
The living statue: Performer, poseur, posthuman
}

\section{Andy Lavender}

\begin{abstract}
This article explores the contemporary phenomenon of living statue performance. It addresses the attributes of this work as a mode of disciplined physical presentation; a cipher for acting; and an instance of pure watchability. I discuss examples of statue performers in Sao Paolo's Parque Ibirapuera, to examine ways in which living statues present personae, interact with spectators and create situations of affect. I note some historical instances of statue performance and their taste for the uncanny. In addressing the recent ubiquity of the form, I argue that today's living statues can be seen as characteristically posthuman and suggest that their tropes of presentation are consistent with other kinds of performance within digital culture.
\end{abstract}

\section{Keywords}

acting

body

living statue

posthumanism

phenomenology

spectating 
When did statue performance begin? I mean the mode of street entertainment in which an individual, usually in all-encompassing costume and make-up, stands still as the public walks past. On the face of it, this is a peculiarly counter-intuitive act. It renounces the usual reaching-out of street performance. It has none of the élan of the juggler, the magician or the daredevil. On the contrary, the statue performer appears remote, placing herself before the public deliberately at one remove, fixed in a personal space of concentrated focus. By way of its visual representation, statue performance is pretending not to be performance at all, and claims to evoke another artwork entirely, the monumental representational sculpture disported around cities worldwide.

Living statues themselves are now widely international. I first properly noticed statue performance in Barcelona in 2000. A number of practitioners were plying their silent trade along La Rambla, Barcelona's celebrated place of promenade. This was the ideal location, as there was a ready public given to strolling at no great speed, and wide walkways in which one could set up in the middle of people's passage without getting in the way. One performer - dressed as a soldier and sprayed from head to toe in a metallic hue that exactly matched the railings on which he stood - was so still, so perfectly turned out, that it took me a while of deliberate scrutiny to ascertain that this really was a human being and not a piece of cast metal. I found this rendition oddly exciting. The performer was in a curious negative space, renouncing the actor's extrusion and extroversion whilst practising a craft in full public view and with considerable skill. Standing still is not easy, let alone remaining in a fixed position without any discernible movement for a prolonged duration. It requires corporeal discipline, sufficient tension to hold the pose, and 
sufficient relaxation not to become overtired or suffer from muscular cramps. This mastery of the body is also a disciplining of the self, which is subjected to a rigorous deprivation (of movement, relaxation, dailyness) that puts the body at the service of the performance.

A challenge ensues, to the performer to maintain position, and the spectator to decipher movement. As statue performer Tom Albert observes:

The two things the crowd wants to catch you on are your breathing and blinking; these are the things that need the most practice to minimise. Yoga and other meditative practices really help in finding total stillness. Pranayama breathing and the Alexander Technique are really useful for getting enough air in without activating unnecessary muscles around your chest and stomach. Once you're frozen, you enter a totally different headspace - time seems to pass quite differently and it's easy to zone out. Swaying very slightly and wiggling fingers or toes keeps the blood moving. ${ }^{1}$

According to Roger 'Gräns' Jonsson, who describes himself as Sweden's first living statue, training as a mime artist is a useful grounding (Jonsson trained at Etienne Decroux's school in Paris).

Dancers tend to want to move, while mime training is a combination of tension and relaxation. It's all about how to relax in one position. To be able to move in 
slow motion you need to be physically trained. That takes a couple of years. (Lindahl 2010)

Ed Johnson of The Living Statue Company remarks that:

It really is a lot harder than it looks. Standing still for anything longer than fifteen minutes can cause some significant pain in the joints, the back and the feet. A professional Living Statue would think nothing of standing still for two hours or more which takes a great deal of concentration and physical control. A performer will take time to slowly control their breathing. Over time it becomes shallow and almost imperceptible - creating the illusion of absolute stillness. Soon the whole body becomes still without a flicker or a twitch. ${ }^{2}$

To this end, the rendition is increasingly admirable as time passes, which means that whilst it appears static the performance is temporally defined, for its effects accumulate chronologically. The statue freezes time in a single gest, whilst the performance gathers over time - and time itself is thereby part of the drama of the living statue. ${ }^{3}$ It is further theatrical in that costume, make-up and pose can all be more or less well achieved, so that registers of aesthetic achievement apply here no less than on more celebrated stages. The absence (usually) of a hinterland of movement, sound and set nonetheless makes the statue a particularly distilled cipher for acting. Performance as a statue can be thought of as complete, in that it requires no other involvement beyond that of the prepared performer. So self-contained is it that we might think it is the form of performance that 
gets closest to not requiring an audience. Yet in this scenario we find not only pure physical presence but also pure watchability, a body submitting to privation in order to be present for viewing (and photographing) from almost any angle, and at unusually intense degrees of scrutiny. The performer is manifest. Whilst this is a clarified instance of display, statue performance also presents a concentrated form of dasein. The performer simply is; in a moment of acted embodiment that is also an instance of being, right under our nose.

Statue performance is strangely nomadic. It depends upon fixity but one can up and off and present one's statue anywhere (within reason). Statue performance usually takes place within a public setting where pedestrians themselves are in drift. The location is typically available for performance as a place of posing and spectating encountered en dérive. The statue creates an urban mise-en-scène that juxtaposes bustle, promenade and perambulation with stillness and separation. It interrupts movement not only by virtue of its own fixity but in the pause it produces in those who pass by. The statue, then, remakes both space and time through an insistent in-action.

Roger Jonsson suggests a cultural reverberation to such refunctioning.

There are so many things that move fast in our society, and suddenly you see a person standing completely still. People think it is cool. Many dream of taking it easy, that's what people miss - to have enough time to themselves and to achieve some sort of harmony. (Lindahl 2010) 
Simon Shepherd makes a related point in his discussion of the emergence of body art in performance: 'Within the counter-culture of the 1960s the body was given value on the basis of its naturalness, the thing humanity had in common, in a society increasingly mechanized, mediated and repressive' (2006: 2). Statue performance has an intriguing relation to naturalness. Looking exactly like a statue - which betokens a form of authenticity - is part of the genre's appeal. The body on display in living statue work is phenomenally distinct, a figure of pure human presence. Yet this is not the fleshy, feeling, bleeding body of late-twentieth-century body art; nor is it the looser, relaxed body of the skateboarder, the free improviser or the stand-up comedian, those other inhabitants of late-twentieth-century performance cultures. This is a disciplined, rigorous, tense body, placed in everyday locations but not of the everyday, effective insofar as it is not at leisure - indeed, insofar as it is unnatural.

\section{Appearances}

The living statue appears in diverse forms of western cultural production throughout history. Some key instances have (so to say) fixed the peculiar fascination of the statueas-flesh. In Greco-Roman mythology the goldsmith Pygmalion made an ivory statue of a woman then fell in love with his artwork. As Ovid recounts:

Often he stretched forth a hand to touch his creation attempting to settle the issue: was it a body, or was it - this he would not yet concede - a mere statue? 
(2005: 350; translator's emphasis)

Pygmalion's wish is granted through the beneficent intervention of Venus ('She is alive! And her veins leap under his fingers!'). Sexual politics aside, in its various manifestations the story concerns the pathos of hyper-naturalism (the seemingly authentic is unobtainable) and the pleasure-principle that underlies theatrical transformation.

The trope of fixed composition was central to the tableaux vivants of the Medieval and Renaissance periods. Presented within festivals, pageants and processions, the tableaux were designed to be immediately 'readable'. R. J. Knecht describes Francis I's entry into Lyon, July 1515:

At intervals along the processional route, which had been decorated with the King's colours, young women stood on pillars, each holding a letter of his name. Between the pillars, tableaux vivants were staged by members of the city's leading families. One showed Francis defending Peace against the Duke of Milan and the Swiss bear; another as Hercules gathering fruit in the garden of the Hesperides. (2004: 20)

Knecht's account indicates the civic and political aspect of the tableau vivant; its production context as an ensemble staging and part of a larger civic mise-en-scène. The latter-day statue is very different, normally detached from any direct reference to civic proceedings and definitively solo. 
Shakespeare's The Winter's Tale (c.1611) combines civic import and virtuoso performance in the scene in which the statue of Queen Hermione comes to life to effect the play's denouement and the more metaphorical thawing of her husband Leontes. In the 1840s the American showman PT Barnum displayed living statues as performance curios, figuring the statue as the object of a spectatorial gaze that was both rewarding (since paid for) and remorseless. The tableau vivant meanwhile became an entertainment staple in different corners of Victorian culture. James H. Head gives advice as to the creation of effective presentations in Victorian parlours:

In forming up a tableau, lights and shades should be studied; in fact, this is the main secret of producing effects, and by managing the lights about the stage correctly, you can throw parts of your picture in shadow, while other portions are light. [...] When the position is once taken, it should be kept, unless it is a very difficult one. [...] In thirty seconds after the second bell, the [stage] manager will ring a third time, which will be a signal for the curtain attendant to draw up the curtain, which should rise slowly to the top of the frame, and be kept up about thirty seconds. Each tableau should be exhibited twice, and in some cases three times. (Head ([1860] 2006)

Here was live performance for an era of pictorialism. This mode found rather different expression in the pose plastique, an eroticized display in theatres and music halls in which one or more women, wearing little or nothing, or costumes that gave the appearance of nothing, displayed themselves in the manner of classical statuary. Poses 
plastiques persisted well into the twentieth century. In her considered blog, statue performer Cady Vishniac suggests that

The success of poses was their downfall. Once it was popularly accepted that women could and would appear naked onstage, there was no need to pretend that they were imitating classical art, and there was no reason they shouldn't dance around a little as they performed - in fact, this was preferable. Eventually, the energetic and straightforwardly lascivious striptease completely replaced the passive pose plastique with its allusions to high art. Almost nobody was impersonating naked statues by the $1950 \mathrm{~s}^{4}$

Differently theatrical, the celebrated play-within-the-film in Marcel Carné's Les Enfants $d u$ Paradis (1945) is set on the pantomime stage of the Théâtre des Funambules. Pierrot, played by Jean-Louis Barrault, falls in love with a statue, played by Arletty, who comes to life in order to make off with Pierrot's rival Harlequin. The film is chiselled out of the constrictions of its wartime production context in the 1940s. Its setting in Paris around 100 years earlier turns it towards a performance genre in which theatrical representation had a clarifying constraint through its wordless precision, not inappropriate to the privations of life and work under Nazi jurisdiction.

In each of these instances there is something productively uncanny in the concentration of performance at the border of life and non-life, a feature exploited in the depiction of the Weeping Angels in the BBC children's science fiction series Doctor Who. Malevolent 
aliens in the form of winged, stone statues, the Angels have the ability to move closer to you as you blink. Introduced to the series in 2007 in the episode 'Blink' (written by Steven Moffat and directed by Hettie MacDonald), they were voted the 'scariest monsters' that year by readers of Doctor Who Adventures magazine, beating even the notorious Daleks. ${ }^{5}$ As the BBC's website informs fans of the programme,

Possessing a natural and unique defence mechanism, the Angels are quantum locked. This means that they can only move when no other living creature, including their own kind, is looking at them. As soon as they are observed, they instantly turn to stone and cannot be killed. ${ }^{6}$

This provides an ingenious riff on the play in statue performance between fixity and fluidity: the Angels move inexorably closer without ever seeming anything other than inanimate. The concept also reverses the statue's usual relationship to death. Rather than commemorate the formerly living, the Weeping Angels harbour life forms that hasten others towards their own oblivion. The fascination with looking that the living statue depends on - indeed produces - is dramatized here as a matter of life and death.

Steven Moffat's Weeping Angels stand alongside the proliferation of living statues as part of a contemporary cultural phenomenon. Indeed since 2005 the city of Arnhem, in Holland, has hosted an annual World Statue Festival. Over 150 artists appeared at the event in 2012, many of them competing for the first prize of 2000 euros awarded to the World Statue Champion. ${ }^{7}$ We might think of contemporary statue performance as 
predominantly a form of street theatre, but it has extended into differently commercial outlets. The UK-based Circus Malabaristas, for instance, notes on its Human Statues home page that

organisers of film premieres, summer balls, corporate events, nightclubs \& promotions have all booked our living statues. ... Live statues form an artistic backdrop for an event (where they remain motionless during their performance) or can periodically come to life to add surprise and comedy to an event. Human Mannequins create a startling reaction at promotional and performance art events. We have provided human mannequins for many stores and festivals. ${ }^{8}$

You can book statues across a range of categories, including for example a Victorian butler and maid, chimney sweep, King Arthur, Neptune, Isambard Kingdom Brunel, the Three Graces and even a pair of acrobats fixed in mid-routine. The agency StreetEnts.co.uk profiles a similar selection on its website: 'Visually stunning and highly interactive they act and react with the audience to create moments of comedy, drama, surprise and sadness. The audience is at first intrigued by the still and silent statues then eager to catch their attention and to create movement'. ${ }^{9}$ Both companies proclaim more than a decade of experience. These and others like them indicate that statue performance has attained a certain corporate feel over the first years of the twenty-first century and has been commoditized as part of a wider economy of specialist but ubiquitous performance practice. 


\section{Interactions}

If the statue is pure presence, prone for viewing, she is also capable of more pronounced action as a joker, a mischievous interactor. The statue may respond to her audience, or surprise passers-by with a sudden sound or movement. This trope separates the public into those that watch, in the know, looking out for the familiar move and its effect of surprise on others, and those that do not suspect (or pay much attention), who are duly surprised. There is a third category, usually comprising children: those who are available for surprise, cautiously approaching the statue, waiting for - daring -it to move, until the anticipated but often-startling moment at which some responsive action is initiated. As Tom Albert observes:

Once I've come to life, I try to use strong, clearly-defined actions - almost stylised. I find this helps draw audience members in from a long distance.

As a performer you're creating a weird and powerful image of total stillness within a sea of movement. It may sound restricting, but it's a surprisingly free medium. Having a distinct character, a set of behaviours and rehearsed actions are major assets. They allow you to improvise freely with audience members while still presenting an identifiable image, which holds a crowd's attention longer. If you can

keep a few tricks up your sleeve for when bigger crowds form, so much the better. ${ }^{10}$

As with any street performance, this mode has its share both of mountebanks and artistes. The individuals who don, say, a Shrek or Mickey Mouse costume and stand around - can we say 'in character?' - on London's South Bank are, I suggest, towards one end of the 
spectrum. By way of examining dimensions of statue performance at points on the scale I will consider three living statues disporting themselves one afternoon in Parque Ibirapuera in Brazil's Sao Paulo. ${ }^{11}$

\section{INSERT FIGURE 1}

Figure 1: A prime pavement position in Sao Paolo's Parque Ibirapuera. (Andy Lavender.

\section{The Mudman}

The statues each stand on a pedestal, a small stage that elevates and marks this as a body in performance. It is hard to say quite what this figure appears as. He is dressed as a sort of mudman, with clay caked over his face, neck and hat, perhaps like a potter who has become his pottery (Figure 1). He wears a long shift of the same straw colour that comes down over his pedestal. There is rather less statue performance here and a good deal more interaction with the passing spectators, calling and gesturing. When a child approaches he gives it a lollipop that he takes from a bag over his left shoulder. This statue is, we might say, motionally incontinent. The performance here is not so much of statuesque virtuosity, more of an age-old something-for-something, the staple of street performance, for which the statue form is simply a vehicle. The child approaches; the child is rewarded; the statue is not infrequently reimbursed. The statue reminds us that fixity of position (however loose the pose) provides for an unthreatening sort of focus. The performer is safely isolated but willingly interactive, a transactional figure in a zone where leisure becomes entertainment. 


\section{The Cowboy}

This performer is dressed as a rancher or cowboy. He performs robotic movements to the sound made by his voice through a swozzle, a diaphanous device that sits on the roof of the mouth and enables a comically rasping utterance, which not only accompanies his actions as a machine-like sound-effect but is also used to communicate with members of the public. As with some of his peers, he presents a sort of mash-up, evoking here four vernacular traditions: the statue, the iconic figure of the cowboy, the robot dancer (popular during the 1980s in tandem with systems-driven synthesizer and computer music), and the visceral vocalscape of the Punch and Judy performer.

Part of the game in statue performance is a negotiation of the line between fixity and interaction, which is to do with timing as much as motion. It can also be teasing. A girl in a pink t-shirt touches the cowboy as he stands fixed, slightly crouched. There is no reaction. A young woman approaches and puts some money in his collecting tin. The statue robotically moves to thank her, extending his hand for a handshake, which is granted. The girl in pink then also donates some money and moves away. The statue beckons her over, and takes her hand - which he then lifts to his lips. As the hand arrives at its destination, the performer freezes (Figure 2). Her hand held aloft, the girl finds herself embarrassedly, laughingly caught in a play on participation, entrapment and the rules of statuedom (the statue will set).The performance is subtly calibrated, judicious, rhythmically controlled, decisively of the moment.

\section{INSERT FIGURE 2}


Figure 2: A frozen kiss. (c) Andy Lavender.

\section{The Poet}

Is this a poet, or a writer? He sits in calm reverie, wearing glasses and with pen poised in his hand. A plaintive song plays from a speaker in the dais on which he sits. A collecting pillar entwined with flowers and a pile of grey tomes completes a small mise-en-scène of mourning or commemoration (Figure 3). He is utterly still, unless someone drops money into the hole at the top of the pillar, at which he slowly inclines his head to thank the giver. He then offers a slip of paper from inside one of the books that he holds which, it turns out, is a box - a prop - rather than a 'practical' book. The slip contains a message in Portuguese: 'Welcome to the city of Sao Paulo! I wish you a beautiful day! ... May your day be peaceful. May you be at peace'.

\section{INSERT FIGURE 3}

Figure 3: A meditative mise-en-scène. (C) Andy Lavender.

This is a performance of patience and endurance, as the performer barely moves but for his graceful transactions with members of the public, conducted in dream-like slow

motion. The statue draws small crowds, who gather, observe, transact and disperse. There is much photographing, sometimes of the statue, sometimes of individuals in interaction with him, and especially when a child approaches and he responds with beneficent calmness. One might say that the statue is a magnet for the child that is a magnet for the camera. Children are offered a brightly coloured plastic ring from the other book-box that 
the writer holds. This performance takes place within a bubble of presence created from small but significant elements of sound, costume, make-up and prop design, shaping a series of intimate, interrelational personal moments.

My own moment proved to be a peculiar non-transaction. The performer settled back into position after a bout of handing out slips, his eyes apparently closed. I approached and dropped a note into his collection box, and retired. Some seconds later, someone else dropped money into the box. The statue opened his eyes, inclined his head and made the usual offer of the slip from his book to the second contributor. As I walked away, a group of passers-by commiserated with me on the strange non-occurrence following my own financial deposit. Perhaps I had simply not been heard, approaching from an oblique angle as the performer settled back into reverie, and posting a silent banknote. Perhaps he was expressing a form of resistance to this guy who had loitered overlong on the edges. Whatever the reason, the incident emphasized the canny structure of this performance of the uncanny, creating an affective space in which the old exchange - money for a show could be transacted with individual attention for a brief special moment. And it revealed another affect: the anticipation of a response, and the simple delight when it comes (or perhaps the disappointment when it does not), the essence of interactivity.

\section{The posthuman statue}

Should we be surprised that living statues have appeared like something of a rash since the turn of the millennium? For all its historical antecedents and detachment from more overt forms of technology, this form of performance resonates with others within digital 
culture. It is individual, even solipsistic. It takes place in public; and yet the self is concealed behind a persona, and may be unrecognizable when she emerges from beneath make-up and costume. These tropes - curated individual presentation, the rendering of a public persona that conceals a reserved private realm, the opening up to spectatorship are features of the way in which individuals engage with social media in digital culture. The fascination with corporeality and the presentation of persona rather than person resonates with other contemporary manifestations of performance.

In The Absent Body, a phenomenological study of corporeality and embodiment, Drew Leder suggests a paradox of bodily presence:

While in one sense the body is the most abiding and inescapable presence in our lives, it is also essentially characterized by absence. That is, one's own body is rarely the thematic object of experience. When reading a book or lost in thought, my own body state may be the further thing from my awareness. I experientially dwell in a world of ideas, paying little heed to my physical sensations or posture. (1990: 1)

I suggest below that this analysis has limitations. Nonetheless, statue performance dramatizes the presence/absence paradox. The living statue presents the figure of someone other than the performer (this is a form of acting, after all), referring beyond the body that expresses the persona. The literal stuff of the performer's veins, musculature and tissue is typically veiled, cloaked both by costume (usually) and the expression of a 
sublimely petrified Other. Taken at face value, the figure is absent in a more literal way, devoid of the life of the persona it is presenting, as with actual statues. Yet herein lies the paradox, for the statue performer also conjures the originary presence of the actor. As Shepherd suggests, the body 'is a living entity that occupies a finite amount of space and has its own mass, energy and motor capacity. It is a material presence. As such it produces knowledge of itself and impacts upon the senses of others' (2006: 6). This is intrinsic to the great dare of statue performance. For we are presented with the inescapable corporeality of the actor along with the actor's effacement in appearing as figure rather than flesh. This moment of presence/absence is affective.

Leder challenges what he sees as a Cartesianism that would relegate the body 'to a secondary or oppositional role, while an incorporeal reason is valorized' (1990: 3). His emphasis on lived experience helps demonstrate that the lived (experienced) body is also a physical (objectified) body, one that can observe itself or be observed. In his concluding chapter 'To Form One Body', he makes a spiritual turn in an attempt to resolve the relation of such a body to a condition of absence. He discusses 'compassion', 'absorption' (by which he means 'aesthetic openness to the world') and 'communion' as modalities of perception and experience that characterize post-Cartesian embodiment (Leder 1990: 161-73). We might not agree with these conclusions, but they are suggestive in relation to the operations of statue performance, which combine corporeal lived experience, an aesthetic figure, and the phenomenological witness of the spectator. Presenting the statue entails a feat of endurance and physical control that gives the performer a developed sense of encounter with her own body. The spectator in this 
scenario cannot but be aware of the testing physical demands made by this performance in its moment. Our response as audience, then, is through an observation that may become a form of absorption (scrutiny and uptake) and assumption (empathy), where we might imagine the physical privation in our own body. The statue dramatizes this tension between (to echo Leder's use of the German terms) Korper, the categorical physical body, and Leib, the lived body that is a vehicle for witness and feeling. Held in pure presence, evocative of absence, the statue performer stages an encounter with the fact of embodiment.

This only partly explains the allure of contemporary statue performance. Written before the advent of the Internet, Leder's account now seems notably pre-digital, and we must turn to a different paradigm (albeit one that is similarly post-Cartesian) to extend the analysis. In her influential account of posthumanism, N. Katherine Hayles is interested in the 'new models of subjectivity' that arise in the computer age (1999: 4).

In the posthuman there are no essential differences or absolute demarcations between bodily existence and computer simulation, cybernetic mechanism and biological organism, robot teleology and human goals. [...] The posthuman subject is an amalgam, a collection of heterogeneous components, a material-informational entity whose boundaries undergo continuous construction and reconstruction.

(Hayles 1999: 3) 
The living statue is a posthuman phenomenon, although not entirely in the terms that Hayles outlines. One of her key propositions is that a dialectic of presence/absence is superceded in digital culture by one of pattern/randomness. As she explains:

[...] information is increasingly perceived as interpenetrating material forms. Especially for users who may not know the material processes involved, the impression is created that pattern is predominant over presence. From here it is a small step to perceiving information as more mobile, more important, more essential than material forms. When this impression becomes part of your cultural mindset, you have entered the condition of virtuality. ... as information becomes more important, the dialectic of pattern/randomness (with which information has deep ties) tends towards ascendancy over the dialectic of presence/absence. (Hayles 1999: 19, 247, original emphasis)

Hayles is careful to emphasize that the former dialectic does not entirely displace the latter- rather, they are in interrelation. She goes on to suggest that dualities may become obsolete over time. We can observe a growing tendency towards hybrid formations in cultural production, and this applies in statue performance as much as it does in other spheres. As Ralf Remshardt notes, 'In the discourse of robotics and cybernetics... posthumanism designates an evolutionary or morphological step towards a synthesis of the organic and mechanical/digital' (2010: 135). The synthesis suggested by the living statue is rather that of the biological and mineral. A decade after the publication of How We Became Posthuman (1999), Hayles notes that her conception of embodiment has 'two 
very distinct connotations. One is human embodiment - or we could even say more broadly "biological" embodiment. ... [The other is] embodiment of material artifacts' (Hayles and Piper 2010: 328) The living statue figures this turn towards materiality through both connotations: biological embodiment and the embodiment of an artifact.

We have already considered the 'originary' body of the performer, authentically feeling and being in the moment, and this brings us to another way in which statue performance resonates with digital culture. The digital age is intrinsically geared around the replication of the perfect copy whilst offering multiple opportunities for individual agency, selfcuration and the publication of one's persona. What is statue performance if not the projection of a copy that is also an original? It is always gesturing at something other than it seems. Profoundly non-technological, the statue is at once an emblem of digital culture: present and remote, figure and flesh, a machine for interaction and spectatorship.

In any event, appearing to be organic and non-organic, the living statue evokes the 'continuous construction and reconstruction' of boundaries that Hayles suggests is characteristic of the posthuman subject. I am not suggesting that the statue performer figures the post-biological in quite the way that Hayles describes, given her focus on information as the generator of virtuality. It is the 'boundary-dissolving' aspect of posthumanism that applies to the living statue (Remshardt 2010: 136). We could rephrase the dialectic here to be that of disposition (posing) and redistribution (taking a different pose), or even structure (fixity) and rupture (unfixing). More productive still is to think of 
these categories as always about to dissolve into each other, in a flow of interrelation. The statue, after all, is alive.

\section{References}

Brecht, Bertolt (1964), 'Short description of a new technique of acting which produces an alienation effect', in John Willett (ed. and trans.), Brecht on Theatre: The Development of an Aesthetic, New York: Hill and Wang, pp. 136-47.

Carné, Marcel (director) and Prévert, Jacques (writer) (1945), Les Enfants du Paradis, France: Pathé Cinema.

Hayles, N. Katherine (1999), How We Became Posthuman: Virtual Bodies in Cybernetics, Literature, and Informatics, Chicago and London: The University of Chicago Press.

Hayles, N. Katherine and Piper, Arthur (2010), 'How We Became Posthuman: Ten Years On: An Interview with N. Katherine Hayles', Paragraph, 33:3, pp. 318-30.

Head, James H. ([1860] 2006), Home Pastimes; Or Tableaux Vivants, South Fairbanks AK: Project Gutenberg eBook \#19724, pp. 19-20, http://www.gutenberg.org/files/19724/19724-h/19724-h.htm. Accessed 5 February 2013. 
Knecht, R. J. (2004), 'Court festivals as political spectacle: The example of sixteenthcentury France', in J. R. Mulryne, Helen Watanabe-O’Kelly and Margaret Shewring (eds), Europa Triumphans: Court and civic Festivals in Early Modern Europe, Volume I, Aldershot and Burlington: Ashgate, pp. 19-31).

Leder, Drew (1990), The Absent Body, Chicago and London: The University of Chicago Press.

Lindahl, Björn (2010), 'Job description: Do as little as possible', Nordic Labour Journal, 2 March 2010, http://www.nordiclabourjournal.org/i-fokus/in-focus-2010/theme-newskills-for-new-jobs-the-nordic-way/job-description-do-as-little-as-possible. Accessed 8 December 2012.

Moffat, Steven (writer), MacDonald, Hettie (director) (2007), 'Blink', Doctor Who, BBC1, 9 June 2007. Available on DVD: Doctor Who: The Complete Series 3, BBC, 2007.

Ovid (2005), Metamorphoses (trans. Charles Martin), New York and London: W. W. Norton \& Company.

Remshardt, Ralf (2010), 'Posthumanism', in Sarah Bay-Cheng, Chiel Kattenbelt, Andy Lavender and Robin Nelson (eds), Mapping Intermediality in Performance, Amsterdam: Amsterdam University Press, pp. 135-139. 
Shepherd, Simon (2006), Theatre, Body and Pleasure, London and New York:

Routledge.

\section{Contributor details}

Andy Lavender is Professor of Theatre and Performance and Head of the School of Arts at the University of Surrey. He is co-editor of Making Contemporary Theatre:

International Rehearsal Processes (Manchester University Press, 2010) and Mapping Intermediality in Performance (Amsterdam University Press, 2010); co-convener of the Intermediality working group of the IFTR; and artistic director of the theatre/performance company Lightwork.

E-mail: a.lavender@surrey.ac.uk

Notes

${ }^{1}$ http://www.theculturalthing.com/the-art-of-the-living-statue, accessed 8 December 2012.

${ }^{2} \mathrm{http}: / / \mathrm{www}$.thelivingstatuecompany.com/resource.html, accessed 8 December 2012.

${ }^{3}$ Statue performance might be thought 'gestic' in the sense that it requires clarity of posture and disposition. It normally evokes an aesthetic of mimesis, however, rather than the more socially purposive aesthetic that Bertolt Brecht espouses in describing gestic acting. See, for instance, Brecht 1964: 136. 
${ }^{4}$ http://movementsinstillness.wordpress.com/2011/01/02/victorian-british-posesplastiques/, accessed 5 February 2013. ${ }^{5}$ http://en.wikipedia.org/wiki/Weeping_Angel, accessed 8 December 2012.

${ }^{6} \mathrm{http} / / / \mathrm{www} \cdot b b c . c o \cdot u k /$ programmes/b00rs69w/profiles/weeping-angels, accessed 8 December 2012. Further fanzine-type information is at http://tardis.wikia.com/wiki/Weeping_Angel.

${ }^{7}$ http://www.worldstatues.nl/en/, accessed 3 January 2013.

${ }^{8} \mathrm{http} / / /$ www.human-statues.co.uk/, accessed 8 December 2012.

${ }^{9}$ http://www.streetents.co.uk/living statues, accessed 8 December 2012.

${ }^{10} \mathrm{http} / / / \mathrm{www}$.theculturalthing.com/the-art-of-the-living-statue, accessed 8 December 2012.

${ }^{11}$ I observed these performances on 29 July 2012. 